\section{Beware of Pyoderma Gangrenosum Complicating Mastopexy: The Importance of Early Detection and Treatment}

Salvatore Taglialatela Scafati ${ }^{1}$, Luigi Scarpato ${ }^{2}$, Giuseppe Tanzillo ${ }^{3}$, Francesco Reho ${ }^{3}$

${ }^{1}$ Unità di Chirurgia Maxillo-Facciale e Chirurgia Ricostruttiva, Ospedale Santa Maria delle Grazie, Pozzuoli, Napoli; ${ }^{2}$ Dermatologist, Private Practice, Napoli; ${ }^{3}$ Divisione di Chirurgia Plastica, Ospedale Universitario di Padova, Padova, Italy

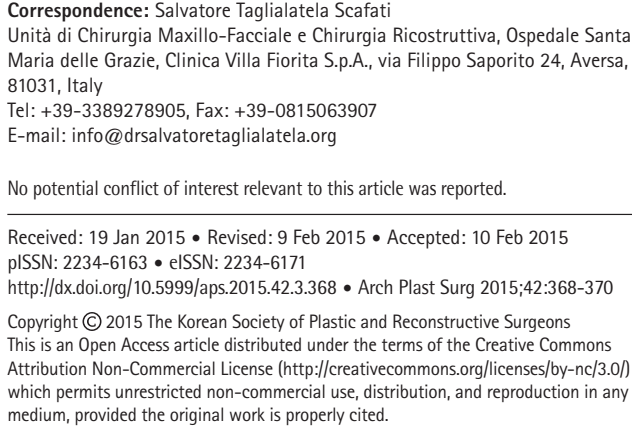

No potential conflict of interest relevant to this article was reported.

Received: 19 Jan 2015 • Revised: 9 Feb 2015 • Accepted: 10 Feb 2015 pISSN: 2234-6163• elSSN: 2234-6171

http://dx.doi.org/10.5999/aps.2015.42.3.368 • Arch Plast Surg 2015:42:368-370

Copyright @ 2015 The Korean Society of Plastic and Reconstructive Surgeons

This is an Open Access article distributed under the terms of the Creative Common Attribution Non-Commercial License (http://creativecommons.org/licenses/by-nc/3.0/) which permits unrestricted non-commercial use, distribution, and reproduction in any medium, provided the original work is properly cited.

Cosmetic breast procedures are widely performed by plastic surgeons all over the world with high satisfaction rate for patients. The most common complications described for reduction mammaplasty and mastopexy are wound dehiscence, breast asymmetry, partial or total loss of the nipple-areolar complex (NAC).

Pyoderma gangrenosum (PG) is a rare ulcerative dermatitis of unclear origins first described in 1930. In most of the cases, it is associated with autoimmune

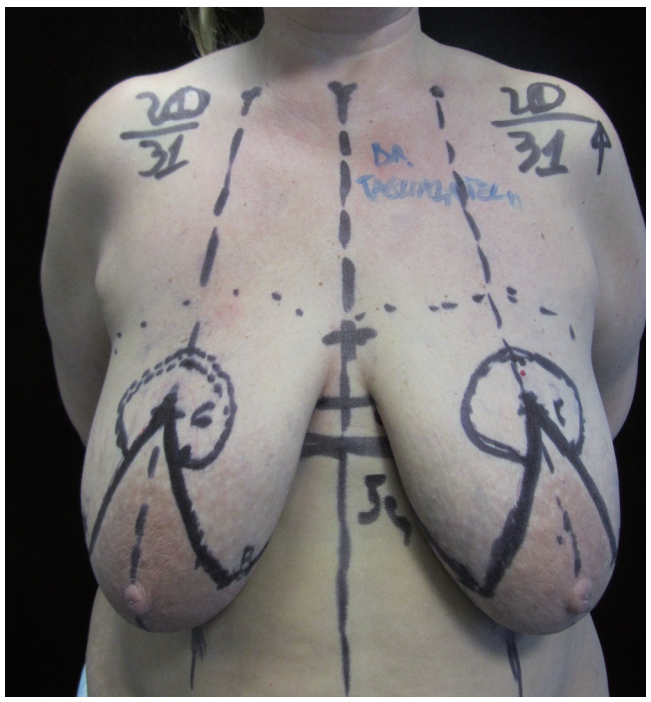

systemic conditions such as Inflammatory Bowel Diseases and several rheumatologic diseases. PG has been reported to occur predominately in lower limbs but any other area of the body can be affected $[1,2]$.

A 50-year-old patient presented to my outpatient clinic seeking mastopexy. She was healthy, non-smoker and reported no history of systemic diseases. After routine consultation, she was scheduled for surgery two weeks later. Surgical plan included autoaugmentation mastopexy using Ribeiro's pedicle and a superomedial pedicle for the NAC (Fig. 1). No breast tissue was discarded during the procedure. Immediate postoperative course was uneventful and patient was discharged the day after the operation.

At 10 day follow-up small ulcerations mimicking a suture reaction were observed along the vertical scar of the right breast and at the level of the left nipple. Conservative treatment was adopted, with general antibiotic ointment and frequent dressing changes. No improvements were noted in the following days: ulcers became larger and painful, increasing patient's discomfort.

Sporadic cases of PG complicating breast procedures have been reported. PG often arises following any trauma, leading to a pathergic phenomenon with catastrophic non-healing wound complications which can cause distress for both the patient and the surgeon [3].

On postoperative day 20, expanding ulcers with purulent-like appearance involving both breasts, resembling wound dehiscence on the right side were noted. PG was suspected and patient scheduled for surgical revision (Fig. 2). Moreover, to exclude any systemic illness associated with PG, patient underwent colonoscopy and serology testing for

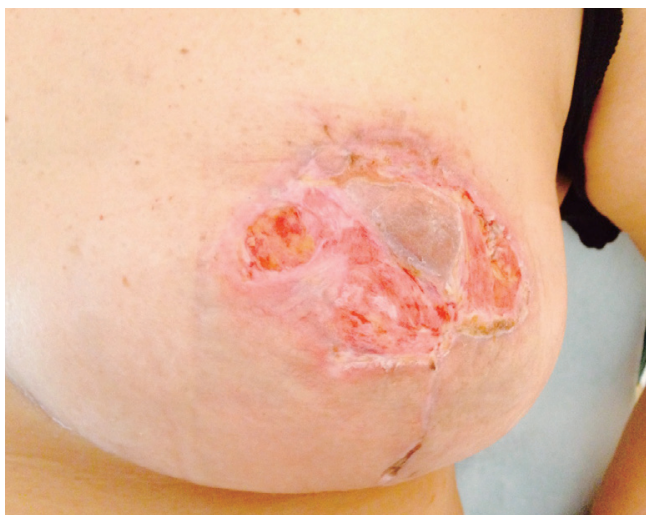

Fig. 2.

Deep ulceration with undermined borders. Involvement of deep dermis and subcutaneous tissue. Note that the nipple is spared. 


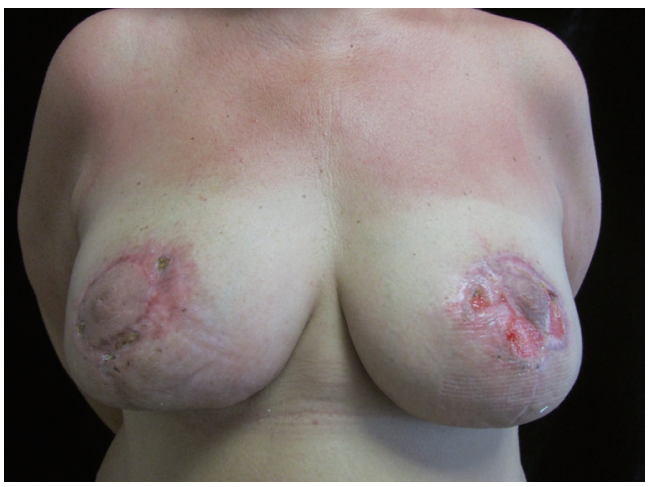

Fig. 3.

Patient at 2 months follow-up. Pyoderma gangrenosum is still present in the left nipple-areolar complex.

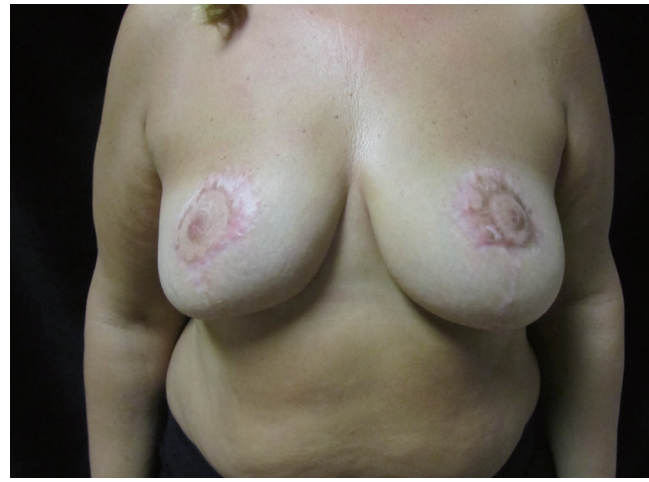

Fig. 4.

Complete remission of the disease at 6 months follow-up.

antinuclear antibodies, lupus anticoagulant, anticardiolipins, cryoglobulin, and anti-neutrophil cytoplasmic antibodies with negative results.

Under local anesthesia, the right vertical breast scar was debrided and accurately closed in two layers using few deep 3-0 Monocryl sutures and separated 4-0 Ethilon sutures for the skin. In the left areolar region, conservative debridement was performed followed by application of antibiotic ointment. Some tissue samples were taken and send for histopathology examination. Eventually, prednisone $(2 \mathrm{mg} / \mathrm{kg} /$ day $)$ was prescribed for 15 days.

At the end of corticosteroid treatment, scar of the right side remained closed and small improvements of the ulcerative condition were observed (Fig. 3). Oral cyclosporine A ( $3 \mathrm{mg} / \mathrm{kg} /$ day) was then prescribed for 3 months at the end of which patient was disease-free.

At 6 months follow-up, complete remission of PG was observed. Scar healing wasgood and small volume deficit was present in the right breast, due to aggressive surgical debridement performed during

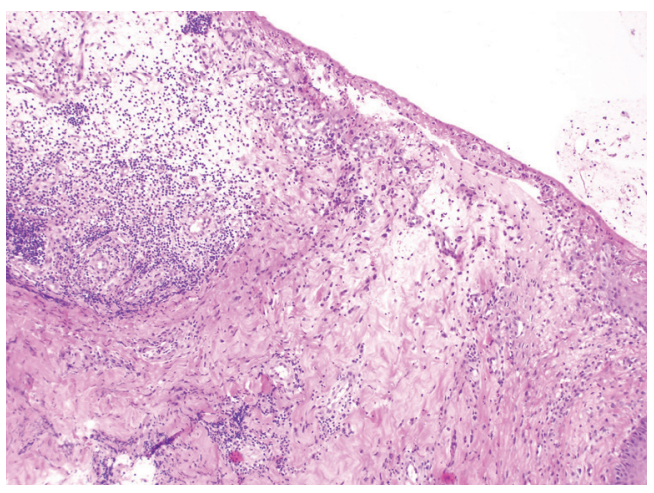

Fig. 5.

Biopsy from the same patient. Wide ulceration with dermal and subdermal abscess. Infiltration of polymorphonuclear leukocytes $\left(H \& E_{1} \times 100\right)$. revision surgery (Fig. 4).

PG is defined as a chronic noninfectious neutrophilic dermatosis. The disease typically starts with one or more pustules and nodules which rapidly evolve in pinkish painful ulcers with usually welldefined and undermined borders; granulation tissue is often present. Nodules and ulcers extend in the skin and in the subcutaneous tissue. In the rare cases occurring after breast surgery, nipples are typically spared. Three others rare variants, the bullous, vegetative and peristomal types, have been also described.

Diagnosis is based on the exclusion of local complications such has wound infection or other types of cellulitis, and of any underlying systemic autoimmune conditions.

Histological findings (Fig. 5) are not specific, showing epidermal and dermal tissue necrosis with intense suppurative neutrophilic infiltration, often associated with a perivascular lymphocityc component and fibrinoid necrosis [4].

Management of PG often requires a multidisciplinary approach. Corticosteroids are usually effective in the acute phase but treatment with more effective drugs should be prolonged for 3-6 months to avoid the risk of recurrence. Cyclosporine A, azathioprine,

mycophenolate mofetil and other immunosoppressive agents represent the gold standard. Adjunctive therapy with topical tracolimus also proved to be effective

[5]. Surgical management by means of surgical revision alone should be avoided for the risk of wound enlargement with subsequent worsening of the lesions.

Presentation of PG affecting the breast can be subtle and its diagnosis challenging. This dermatosis should be suspected in any breast surgery case when apparently inexplicable ulcerative wound healing impairment occurs. Although rare after surgery, early recognition of pathognomonic signs is essential for effective treatment with immunosuppressive therapy and local wound care. 


\section{References}

1. Gonzalez-Moreno J, Ruiz-Ruigomez M, Callejas Rubio $\mathrm{JL}$, et al. Pyoderma gangrenosum and systemic lupus erythematosus: a report of five cases and review of the literature. Lupus 2015;24:130-7.

2. Schoemann MB, Zenn MR. Pyoderma gangrenosum following free transverse rectus abdominis myocutaneous breast reconstruction: a case report. Ann Plast Surg 2010;64:151-4.

3. Tuffaha SH, Sarhane KA, Mundinger GS, et al. Pyoderma gangrenosum after breast surgery: diagnostic pearls and treatment recommendations based on a systematic literature review. Ann Plast Surg 2014 Jul 4 [Epub]. http://dx.doi.org/10.1097/ SAP.0000000000000248.

4. Ouazzani A, Berthe JV, de Fontaine S. Post-surgical pyoderma gangrenosum: a clinical entity. Acta Chir Belg 2007; 107:424-8

5. Doren EL, Aya-ay ML. Pyoderma gangrenosum following breast reduction: treatment with topical tacrolimus and steroids. Aesthet Surg J 2014;34:394-9.

Warthin's Tumor of the Parotid Enlarged by a Facelift Suture

Bommie Florence Seo, Il O Jung, Suk-Ho Moon, Jong Won Rhie, Sang Tae Ahn, Deuk Young Oh

Department of Plastic Surgery, Seoul St. Mary's Hospital, The Catholic University of Korea College of Medicine, Seoul, Korea

Correspondence: Deuk Young Oh

Department of Plastic Surgery, Seoul St. Mary's Hospital, The Catholic University of Korea College of Medicine, 222 Banpo-daero, Seocho-gu, Seoul 137-701, Korea

Tel: +82-2-2258-2842, Fax: +82-2-594-7230, E-mail: ohdeuk1234@hanmail.net

No potential conflict of interest relevant to this article was reported.

Received: 7 Feb 2014 • Revised: 11 Aug 2014 • Accepted: 12 Aug 2014 pISSN: 2234-6163 • elSSN: 2234-6171

http://dx.doi.org/10.5999/aps.2015.42.3.370 • Arch Plast Surg 2015;42:370-372

Copyright (C) 2015 The Korean Society of Plastic and Reconstructive Surgeons This is an Open Access article distributed under the terms of the Creative Commons Attribution Non-Commercial License (http://creativecommons.org/licenses/by-nc/3.0) which permits unrestricted non-commercial use, distribution, and reproduction in any medium, provided the original work is properly cited.

Warthin's tumor is the second most common benign neoplasm of the salivary gland, consisting of epithelial and lymphoid components. It is generally asymptomatic and slowly growing. Sudden increase in its size is usually a consequence of malignant change, or inflammation.

We report a case of a 48-year-old male presenting with a recently enlarged mass of the left parotid gland. He had undergone a facelift procedure with barbed suture, a "threadlift" before this change in size. Histopathological findings reported a Warthin's tumor with focal inflammation. The tumor with its embedded suture material was totally excised without complications.

Facelift methods have evolved over the past several decades, and many patients prefer minimally invasive procedures including suture suspension techniques. Although rare, such procedures should be performed after thorough evaluation and management of any pre-existing conditions however benign they may seem.

A 48-year-old male presented with a rapidly growing mass in his left preauricular area. The patient had had a small mass in this area, approximately 5 $\mathrm{mm}$ in diameter since about 15 years ago, and did not recall any period of notable growth before. Sudden growth in size began one month prior to his visit, with no history of preceding infection or trauma. $\mathrm{He}$ had received a facelift procedure three months beforehand.

Physical examination revealed a firm, fixed, nontender mass with a dimension of about $3 \times 2 \mathrm{~cm}$. The overlying skin had no infection signs, and facial

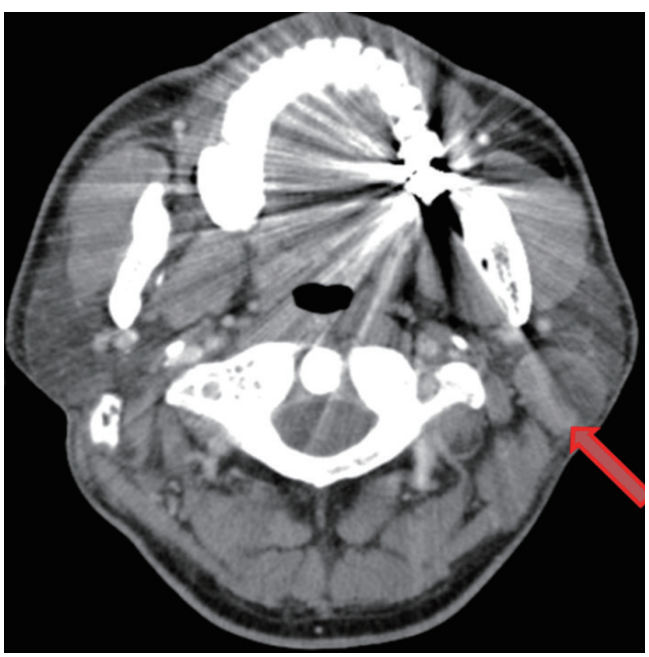

Fig. 1.

Preoperative computed tomography findings show heterogeneously enhancing mass (red arrow) with mixed densities measuring about $2.6 \times 2.6 \mathrm{~cm}$ in the posterior aspect of the left parotid gland. Left internal jugular lymph nodes were also enlarged. 